\title{
RANCANG BANGUN APLIKASI PENGELOLAAN TUGAS AKHIR DENGAN MENERAPKAN PRINSIP-PRINSIP TEKNOLOGI MOBILE
}

\author{
Julianto Simatupang1), Muhammad²) \\ 1,2 Manajemen Informatika, Akademi Manajemen Informatika dan Komputer Mahaputra Riau, Jl. H.R. \\ Subrantas No. 77 Panam Pekanbaru - Riau - Indonesia \\ Email: ${ }^{1}$ julianto.amp@gmail.com, amp.2muhammad090888@gmail.com
}

\begin{abstract}
The implementation of the final assignment has become an annual activity for universities, even in large campuses this has become a semester activity. The management of a good final project is of course with the right technology support to become a dream together with universities, especially the managers of study programs as academic implementers. The current obstacle faced by AMIK informatics management study program Mahaputra Riau is that it is difficult to get progress information on the final task quickly and precisely. This is because the final task management process is still done in a conventional way, namely by using quite a lot of forms and document requirements, and the submission is very limited by place / space and time because students must come to campus to submit the final project title. From these limitations and information needs this study aims to design a final task management application by applying mobile principles. So that information and submission of tasks can be accessed quickly, precisely and accurately. The methodology used in this research is the method of analysis and design. The results obtained from this study are mobile-based final submission applications that can be used to submit titles and access information on the implementation of final assignments anytime and anywhere. With this application, students are expected to be able to submit final assignments easily and quickly and obtain real-time final assignment information.
\end{abstract}

Keywords: Final project, application, mobile

\begin{abstract}
Abstrak
Pelaksanaan tugas akhir telah menjadi kegiatan tahunan bagi perguruan tinggi, bahkan dikampuskampus besar hal ini telah menjadi kegiatan semesteran. Pengelolaan tugas akhir yang baik tentunya dengan dukungan teknologi yang tepat menjadi cita-cita bersama perguruan tinggi khususnya para pengelola program studi sebagai pelaksana akademik. Kendala yang dihadapi prodi manajemen informatika AMIK Mahaputra Riau saat ini adalah sulitnya mendapatkan informasi progress pelaksanaan tugas akhir dengan cepat dan tepat. Hal ini dikarenakan proses pengelolaan tugas akhir masih dilakukan dengan konvensional yaitu dengan menggunakan formulir dan dokumen persyaratan yang cukup banyak, serta pengajuannya sangat dibatasi oleh tempat/ruang dan waktu karena mahasiswa harus datang ke kampus untuk mengajukan judul tugas akhir. Dari keterbatasan dan kebutuhan informasi tersebut penelitian ini bertujuan untuk merancang aplikasi pengelolaan tugas akhir dengan menerapkan prinsip-prinsip mobile. Sehingga informasi dan pengajuan tugas dapat diakses dengan cepat, tepat dan akurat. Metodologi yang digunakan dalam penelitian ini adalah metode analisis dan perancangan. Hasil yang didapatkan dari penelitian ini adalah aplikasi pengajuan tugas akhir berbasis mobile yang dapat dimanfaatkan untuk mengajukan judul dan mengakses informasi pelaksanaan tugas akhir kapan saja dan dimana saja. Dengan aplikasi ini diharapkan mahasiswa dapat mengajukan tugas akhir dengan mudah dan cepat serta memperoleh informasi tugas akhir real-time.
\end{abstract}

Kata Kunci: Tugas akhir, aplikasi, mobile

\section{PENDAHULUAN}

Tugas akhir merupakan karya ilmiah dari mahasiswa tingkat akhir yang akan menyelesaikan pendidikannya pada jenjang pendidikan tinggi. Pelaksanaan tugas akhir merupakan kegiatan tahunan yang dilaksanakan program studi AMIK Mahaputra
Riau. Oleh karena itu perlu perencanaan dan pelaksanaannya dilakukan dengan baik. Saat ini pengelolaan tugas akhir masih dilakukan dengan manual, dimana mahasiswa mengajukan tugas akhir dengan mengisi formulir pengajuan tugas akhir. 
Setelah itu mahasiswa melampirkan persyaratan tambahan dan memasukkan seluruh dokumen ke dalam map. Kemudian mahasiswa menyerahkan ke program studi supaya dilakukan seleksi. Disamping itu juga prodi hanya bisa memeriksa judul yang masuk apabila sedang berada di lingkungan kerja, Sehingga proses pemeriksaannya terbatas. Hal tersebut menjadi tidak efisien dan efektif karena membutuhkan waktu yang lama dalam pemeriksaan dan pembuatan laporan pengajuan judul.

Sistem aplikasi menjadi solusi dalam pengelolaan tugas akhir, karena dapat mendukung pengolahan data yang cepat, tepat dan akurat. Oleh karena itu, untuk mengatasi kendala dalam pengelolaan tugas akhir maka perlu pengembangan aplikasi pengelolaan tugas akhir. Sehingga diharapkan pengelolaannya dapat dilakukan dengan mudah. Sistem aplikasi dimaksud harus didukung dengan teknologi terbarukan.

Teknologi mobile salah satu perangkat teknologi yang perkembangannya sangat pesat, hal ini didorong perangkat mobile yang multifungsi, selain alat komunikasi, mobile menjadi salah alat pencari informasi yang paling banyak digunakan saat ini. Karena perangkat mobile sangat mendukung berbagai aplikasi yang bisa dijalankan diperangkat mobile yang dapat membantu para pengguna mobile dalam mengakses informasi yang update..

Penelitian terkait tugas akhir, pengembangan aplikasi bimbingan tugas akhir mahasiswa berbasis website pada program studi pendidikan guru sekolah dasar FKIP universitas riau oleh Eddy Noviana, Otang Kurniaman, Muhammad Nailul Huda. Aplikasi dibangun berbasis web dan Penelitian ini fokus pada bimbingan tugas akhir dan sifatnya mengukur efektifitas pemanfaatan aplikasi terhadap pelaksanaan bimbingan tugas akhir. Perancangan Aplikasi Daring Bimbingan Tugas Akhir, oleh Helen Sastypratiwi, Aprillita Dwiyan. Penelitian ini digunakan sebagai media kordinasi antara pembimbing terhadap mahasiswa bimbingannya. Aplikasi ini dibangun berbasis web.

Dari beberapa penelitian yang disebutkan diatas semuanya dibangun berbasis web. Dimana hasilnya adalah web aplikasi, yang mengharuskan setiap orang yang mengakses harus mengetahui alamat dan portal. Kelemahannya tidak semua user/pengguna bisa mengingat alamat atau portal setiap waktu.

Beberapa keunggulan dari mobile aplikasi yaitu dapat diakses secara langsung dengan hanya menekan icon di smartphone tanpa harus caritahu alamat URL. Pengguna dapat memantau setiap saat informasi ter-update mengenai progress tugas akhir.

Berdasarkan uraian diatas, maka diusulkan pengembangan sistem aplikasi pengelolaan tugas akhir berbasis mobile, tujuannya agar proses pengajuan tugas akhir dapat dilakukan dengan mudah. Mahasiswa dapat mengajukan judul dimana saja dan kapan saja tanpa dibatasi ruang dan waktu. Dengan sistem aplikasi ini, efisiensi dan efektifitas pengelolaan tugas akhir dapat dicapai. 
METODE PENELITIAN

Tahapan. Gambar 1 merupakan metode penelitian yang digunakan untuk melakukan pengembangan sistem aplikasi pengelolaan tugas akhir.

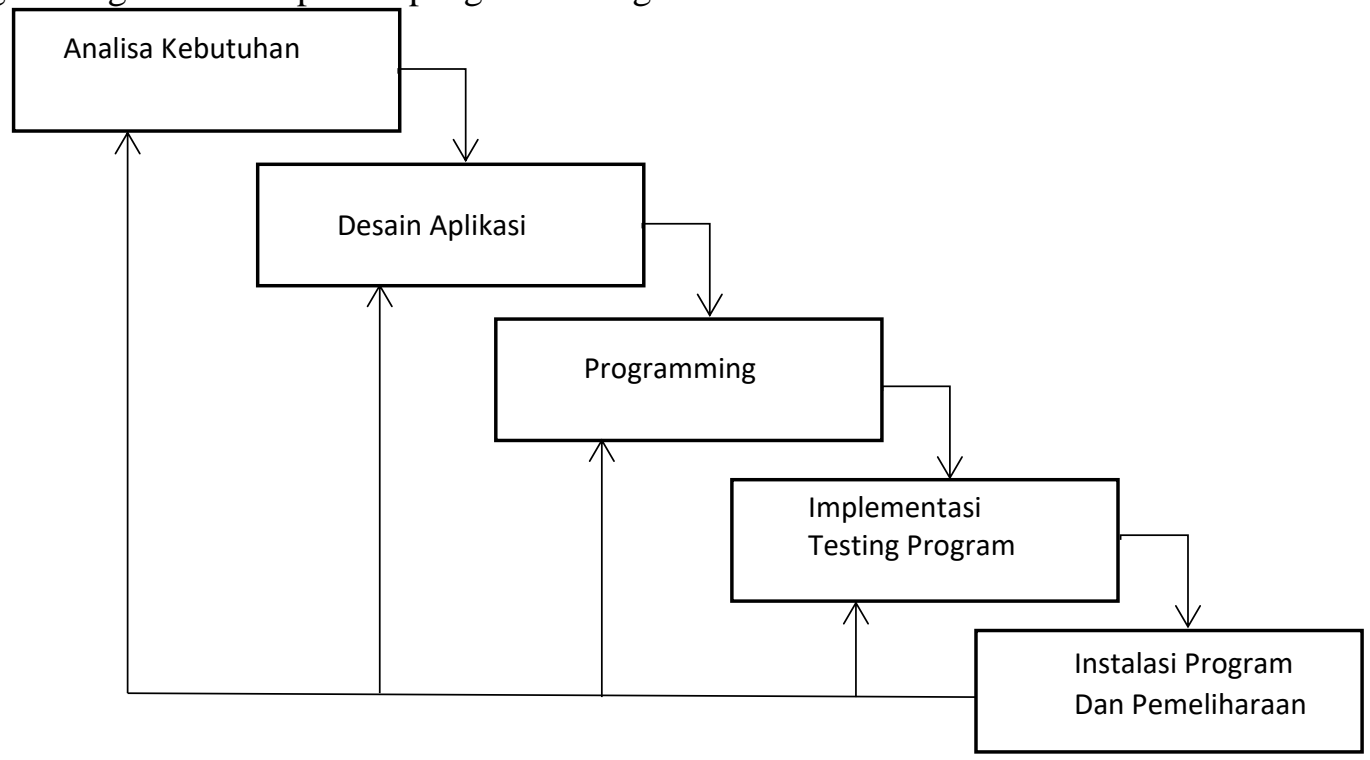

Gambar 1. Model Waterfall

Keterangan:

1. Analisa Kebutuhan

Pada tahap ini dilakukan analisa terhadap proses bisnis yang ada dan mengidentifikasi kebutuhan informasi. Sehingga diperoleh informasi terkait kebutuhan sistem. Pengumpulan data dalam tahap ini dilakukan wawancara atau studi literatur. Tahapan ini akan menghasilkan dokumen user requirment atau bisa dikatakan sebagai data yang berhubungan dengan keinginan user dalam pembuatan sistem. Dokumen inilah yang akan menjadi acuan sistem analis untuk merancang atau mendesain sistem.

\section{Desain Aplikasi}

Pada tahapan ini dilakukan perancangan dengan menggunakan perangkat pemodelan sistem. Hal ini dilakukan untuk memodelkan sistem aplikasi yang akan dibangun.

3. Programming

Tahapan ini merupakan proses penerjemahan desain aplikasi ke dalam bahasa pemrograman. Hal ini merupakan transformasi dari proses manual menjadi terkomputerisasi.

\section{Pengujian (Testing)}

Tahapan ini dilakukan pengujian terhadap sistem untuk mengukur ke efektifan dan kemampuan sistem yang dibangun. Sekaligus dilakukan perbaikan-perbaikan bilamana ditemukan kekurangan-kekurangan dalam sistem. Sehingga sistem benar-benar siap untuk diterapkan.

5. Instalasi Program dan Pemeliharaan Pada tahapan ini dilakukan instalasi program untuk menerapkan sistem aplikasi tugas akhir. Seiring waktu juga dilakukan dokumentasi dan pemeliharaan. Karena permintaan pelanggan berubah sewaktu-waktu.

\section{Android Platform Masa Depan}

Android merupakan salah satu platform mobile pertama yang lengkap, terbuka, dan bebas.

a. Lengkap (Complete Platform): Memungkinkan para desainer untuk melakukan pendekatan secara komprehensif ketika mereka sedang mengembangkan platform android. Android juga merupakan sistem operasi yang aman dan banyak menyediakan tools dalam membangun software dan pengembangan aplikasi.

b. Terbuka (Open Source Platform) Platform android disediakan melalui lisensi opensource. Pengembang dapat dengan bebas untuk mengembangkan aplikasi.

c. Free (Free Platform) android adalah platform/aplikasi yang bebas untuk develop. Tidak ada lisensi atau biaya royalti untuk dikembangkan pada platform android. Aplikasi android dapat 
didistribusikan dan diperdagangkan dalam bentuk apapun.

\section{Prinsip-Prinsip Teknologi Mobile}

1. Pikat Saya

Senangkan saya dengan cara yang mengejutkan. Permukaan yang cantik, animasi yang ditempatkan dengan hati-hati, atau efek suara di saat yang tepat sungguh menyenangkan untuk dinikmati. Efek yang lembut menimbulkan perasaan serba mudah dan kesadaran bahwa kekuatan yang bisa diandalkan ada dalam genggaman.

2. Objek sungguhan lebih menyenangkan daripada tombol dan menu.

Biarkan orang langsung menyentuh dan memanipulasi objek dalam aplikasi Anda. Ini mengurangi upaya kognitif yang diperlukan untuk menjalankan tugas sekaligus membuatnya lebih memuaskan secara emosional.

\section{Biarkan saya memilikinya}

Orang suka menambahkan sentuhan pribadi karena membantu mereka merasa betah dan memegang kendali. Memberikan default yang pantas dan indah, tetapi juga mempertimbangkan penyesuaian opsional yang menyenangkan, yang tidak mengganggu tugas utama.

\section{Kenali saya}

Pelajari preferensi orang dari waktu ke waktu. Daripada meminta mereka untuk membuat pilihan yang sama berulang-ulang, tempatkan pilihan sebelumnya agar mudah dijangkau.

\section{Sederhanakan Hidup Saya}

Persingkat. Gunakan frasa pendek dengan kata-kata sederhana. Orang cenderung melewatkan kalimat-kalimat panjang.

6. Gambar lebih cepat dibanding kata-kata Pertimbangkan menggunakan gambar untuk menjelaskan gagasan. Gambar menarik perhatian orang dan bisa jauh lebih efisien dibanding kata-kata.

7. Putuskan untuk saya tetapi biarkan saya yang menentukan.

Gunakan tebakan terbaik Anda dan bertindaklah daripada meminta terlebih dahulu. Terlalu banyak pilihan dan keputusan membuat orang tidak suka. Untuk berjaga-jaga jika Anda salah, izinkan 'pembatalan.

8. Cukup tunjukkan yang saya perlukan ketika saya memerlukannya.

Orang merasa kewalahan ketika melihat terlalu banyak hal sekaligus. Uraikan tugas dan informasi menjadi potongan-potongan kecil yang mudah dicerna. Sembunyikan opsi yang tidak perlu pada saat ini, dan ajari orang sambil jalan.

9. Saya harus selalu tahu di mana saya berada.

Beri orang kepercayaan diri bahwa mereka tahu di mana berada. Buat agar tempat-tempat dalam aplikasi Anda terlihat berbeda dan gunakan transisi untuk menunjukkan hubungan antar layar. Berikan umpan balik tentang tugas yang sedang berlangsung.

\section{Jangan sekali-kali menghilangkan milik saya}

Simpan apa yang telah susah-payah dibuat orang dan biarkan mereka mengaksesnya dari mana saja. Ingat pengaturan, sentuhan pribadi, dan kreasi lintas ponsel, tablet, dan komputer. Itu membuat pemutakhiran menjadi hal termudah di dunia.

\section{Jika terlihat sama, seharusnya fungsinya sama}

Bantu orang merasakan perbedaan fungsional dengan membuat mereka terlihat berbeda daripada mirip. Hindari mode, yaitu tempat yang terlihat mirip tetapi berbeda fungsinya pada input yang sama.

\section{Sela saya jika penting saja}

Layaknya asisten pribadi yang baik, lindungi orang dari detail yang tidak penting. Orang ingin tetap fokus, dan kecuali jika memang penting dan sensitif waktu, interupsi bisa melelahkan dan menjengkelkan.

\section{Buat Saya Terpesona}

Beri saya trik yang efektif di mana saja. Orang merasa senang ketika mereka memahami sendiri sesuatu. Jadikan aplikasi Anda lebih mudah dipelajari dengan memanfaatkan pola visual dan memori otot dari aplikasi Android lainnya. Misalnya, gerakan menggeser dapat menjadi pintasan navigasi yang bagus. 
14. Bukan salah saya

Bersikap ramahlah dalam meminta orang untuk melakukan koreksi. Mereka ingin perbaikan yang jelas tetapi lepaskan mereka dari detail teknis. Jika Anda dapat memperbaikinya secara diam-diam, tentu lebih baik.

\section{Berikan dorongan}

Uraikan tugas-tugas rumit menjadi langkahlangkah kecil yang dapat dilakukan dengan mudah. Beri umpan balik tentang tindakan, meskipun hanya sesuatu yang sederhana.

16. Lakukan pekerjaan yang sulit untuk saya. Buatlah pemula merasa seperti ahli dengan memungkinkan mereka untuk melakukan halhal yang mereka pikir tidak akan bisa. Misalnya, pintasan yang menggabungkan beberapa efek foto dapat membuat foto amatir terlihat mengagumkan hanya dalam beberapa langkah.

\section{Percepat hal penting}

Tidak semua tindakan itu sama. Putuskan apa yang terpenting dalam aplikasi Anda dan permudah untuk menemukannya serta cepat merasa pintar ketika menggunakan aplikasi Anda. Jika terjadi kesalahan, berikan petunjuk

untuk digunakan, seperti tombol rana pada kamera, atau tombol jeda pada pemutar musik.

\section{Pengembangan Sistem}

Perancangan sistem menjelaskan tentang alur prosedur atau proses bisnis sistem yang akan dibangun. Dalam pengembangan sistem aplikasi pengelolaan tugas akhir menggunakan model berorientasi objek yaitu Unified Modelling Language (UML). Adapun Diagaram yang dipakai untuk mengambarkan fungsionalitas dari pada sistem yang akan dibuat dengan menggunakan Usecase Diagaram. Use Case mendeskripsikan interaksi tipikal antara para pengguna sistem dengan sistem itu sendiri, dengan memberi sebuah narasi tentang bagaimana sistem tersebut digunakan. Secara kasar, use case digunakan untuk mengetahui fungsi apa saja yang ada di dalam sebuah sistem informasi dan siapa saja yang berhak menggunakan fungsifungsi itu. Gambar 2 berikut ini merupakan use

Use case diagram sistem aplikasi pengajuan tugas akhir yang dibangun yaitu :

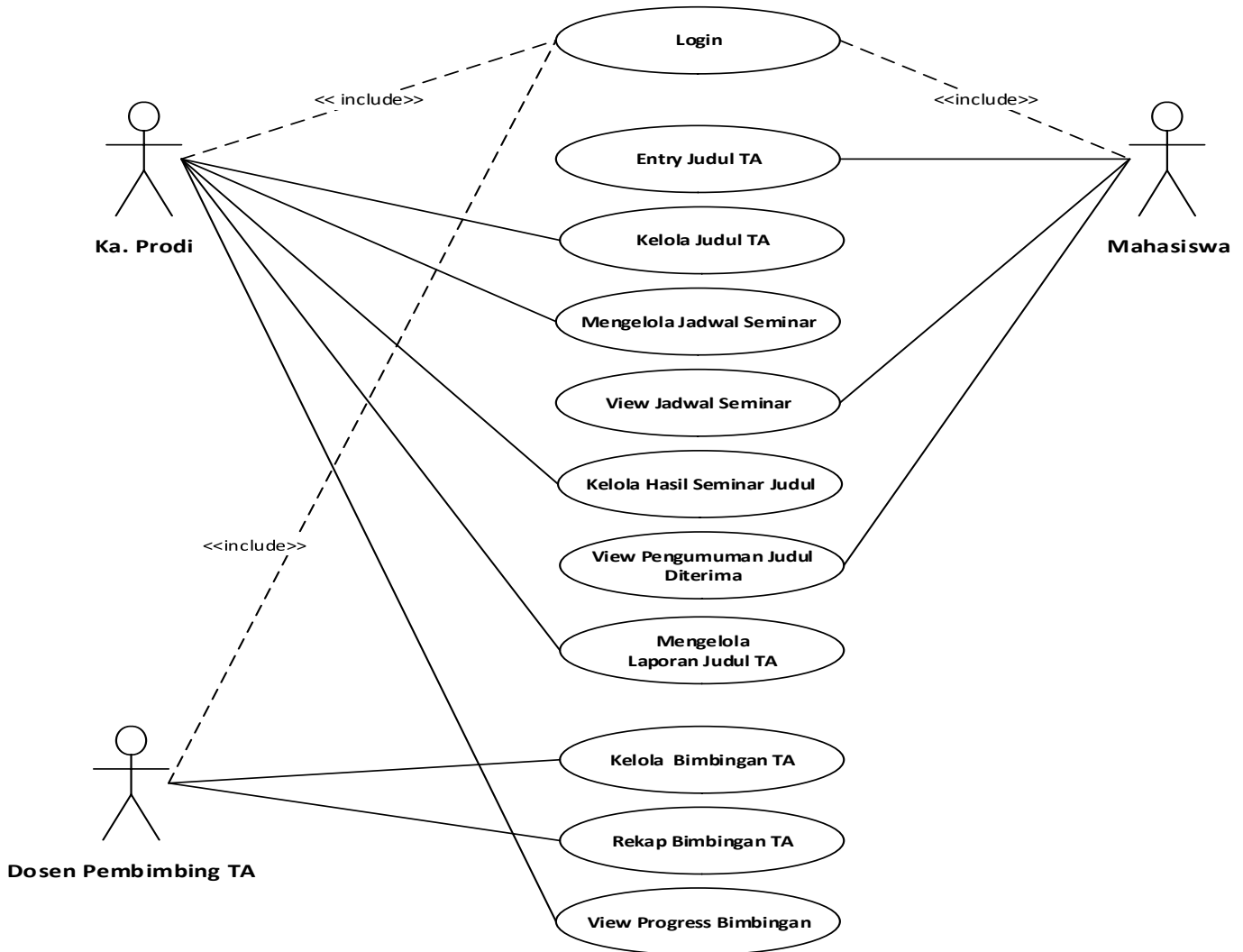

Gambar 2. Use Case Diagram Sistem Aplikasi Pengelolaan Tugas akhir 


\section{Teknik Pengumpulan Data}

Data yang digunakan dalam penelitian ini adalah data primer dan data skunder. Data primer adalah data yang diproleh secara langsung dari sumber asli ( tidak melalui perantara). Data primer pada penelitian ini diproleh melalui wawancara, quesioner dan observasi, yaitu :

1. Wawancara langsung dengan mahasiswa tingkat akhir yang sedang melaksanakan tugas akhir.

2. Menyebarkan quesioner kepada mahasiswa tingkat akhir yang sedang melaksanakan tugas akhir.

3. Mengamati aktivitas dan kegiatankegiatan yang dilakukan oleh mahasiswa tingkat akhir yang akan dan sedang melaksanakan tugas akhir.

Data sekunder merupakan sumber data penelitian yang diproleh peneliti secara tidak langsung melalui media perantara. Data sekunder umumnya berupa bukti, catatan atau laporan histori yang telah tersusun dalam arsip. Data sekunder pada penelitian ini diproleh melalui pengambilan data terkait, yaitu :

1. Mengumpulkan data hasil wawancara mahasiswa tingkat akhir yang akan dan sedang melaksanakan tugas akhir.
2. Mengumpulkan data quesioner yang sudah di isi oleh mahasiswa tingkat akhir.

3. Mengumpulkan data mahasiswa tingkat akhir yang sedang tugas akhir.

\section{HASIL DAN PEMBAHASAN}

Hasil dari penelitian ini adalah berupa sistem aplikasi pengelolaan tugas akhir. Dimana aplikasi ini dibagi menjadi dua halaman dan hak akses. Halaman pertama adalah halaman admin, pada halaman ini admin mengelola seluruh menu aplikasi yang ada pada aplikasi. Untuk halaman admin ini dibangun dengan WEB. Sementara halaman berikutnya adalah halaman mahasiswa. Halaman ini dibangun berbasis mobile. Pada halaman ini mamasiswa dapat mengajukan tugas akhir dan melihat informasi kelulusan tugas akhir melalui smartphone yang mereka punya.

Berikut merupakan hasil dan implementasi Sistem Aplikasi Pengelolaan tugas Akhir berbasis Mobile, tujuannya adalah untuk memperlihatkan antar muka sistem dan fungsi serta kegunaan dari masing-masing modul.

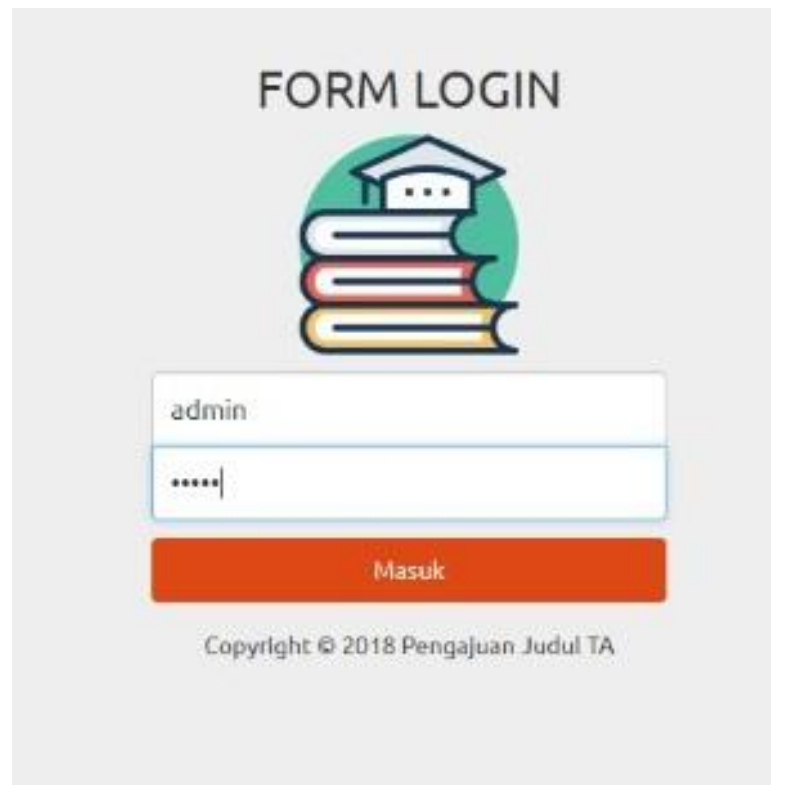

Gambar 3. Login Admin

Login merupakan halaman awal sebagai pintu masuk untuk aplikasi pengelolaan tugas akhir. Pada laman ini sistem akan meminta user untuk memasukkan username dan password.
Kemudian sistem akan memverifikasi username dan password. Apabila berhasil maka akan dilanjutkan untuk menampilkan menu dashboard untuk admin. 


\section{Dashboard}

Selamat datang dl dashboard achin

\section{Gambar 4. Dashboard}

Dashboard merupakan menu tampilan awal setelah berhasil login. Laman ini hanya muncul pada pengguna sebagai admin.

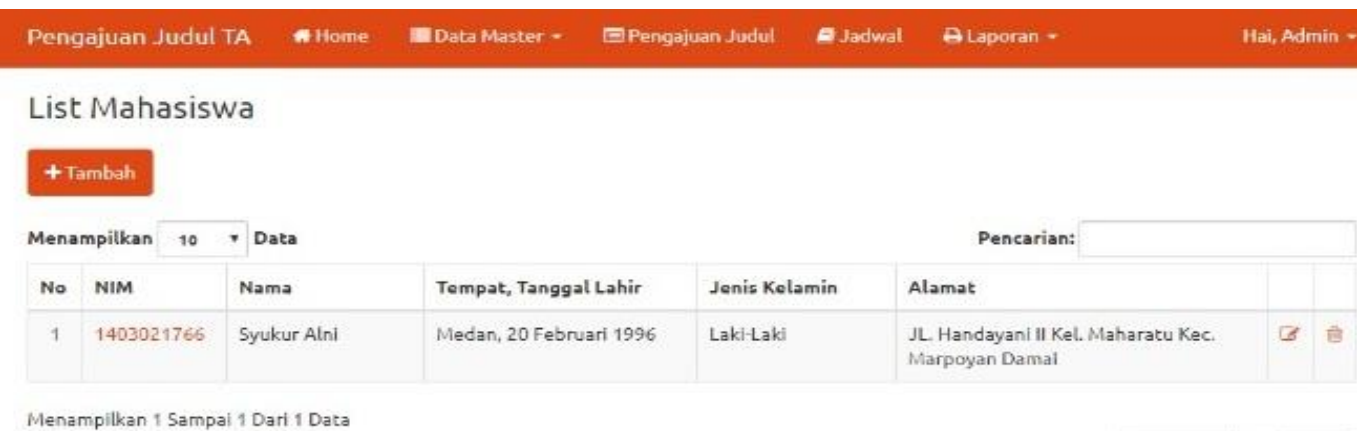

\section{Gambar 5. List Mahasiswa}

Laman list Mahasiswa berfungsi untuk mengelola data mahasiswa. Pada laman ini admin melakukan manipulasi data mahasiswa seperti manambah, mengedit, dan menghapus.

\section{Pengajuan Judul TA AHome EData Master - EPengajuan Judul E Jadwal elaporan - Hal, Admin -}

\section{List Pengajuan Judul}

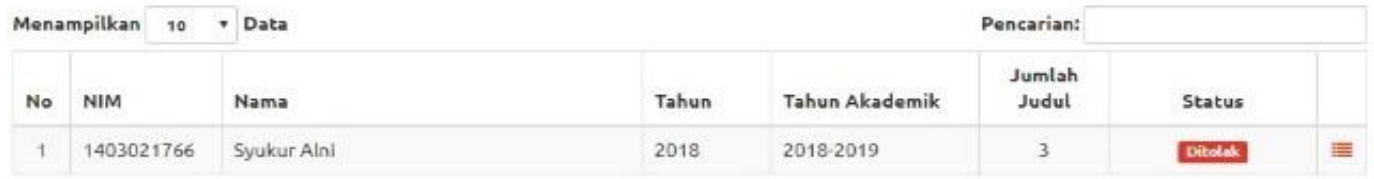

Menampilkan 1 Sampai 1 Dari 1 Data

\section{Gambar 6. List Pengajuan Judul}

Laman list pengajuan judul berfungsi untuk mengelola data judul yang masuk. Pada laman ini admin melakukan persetujuan judul yang masuk dengan merubah status judul.

\section{Halaman Mahasiswa}

Halaman ini dibangun dengan teknologi berbasis mobile, untuk pengembangannya penulis menggunakan android studio. Halaman ini berfungsi sebagai media untuk pengajuan judul tugas akhir 
mahasiswa. Dalam halaman mahasiswa ini terdapat beberapa modul seperti: Login, Beranda, dan Pengajuan Judul. Berikut ini adalah Deskripsi interface dan modul mahasiswa.

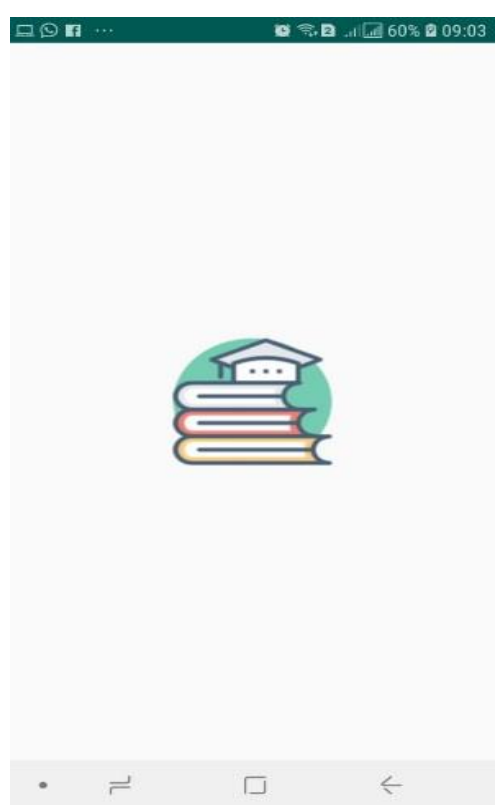

\section{Gambar 7. Icon Aplikasi Tugas Akhir Pada Smart Phone}

Gambar diatas adalah icon aplikasi pengajuan tugas akhir pada layar smartphone. Mahasiswa cukup menekan icon tombol tersebut untuk masuk ke halaman pengajuan tugas akhir. Setelah menekan icon tersebut sistem akan meminta untuk terlebih dahulu melakukan login. Berikut tampilan halama login pengajuan tugas akhir:

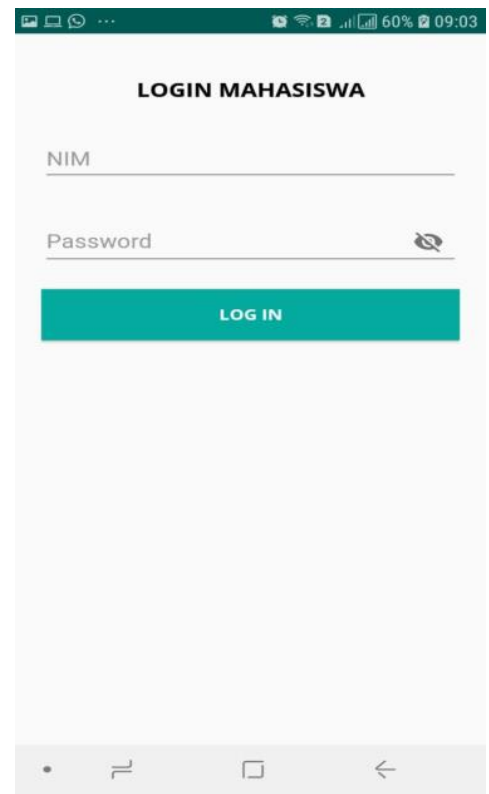

\section{Gambar 8. Halaman Login Mahasiswa}

Gambar diatas merupakan gambar halaman login siswa untuk masuk ke halaman pengajuan judul. Halaman ini berfungsi untuk memverifikasi dan memvalidasi setiap user yang masuk ke sistem, sehingga sistem dapat memfilter user yang masuk ke sistem. Apabila user berhasil login maka dilanjutkan ke halaman beranda pengajuan judul, seperti tampilan gambar berikut : 


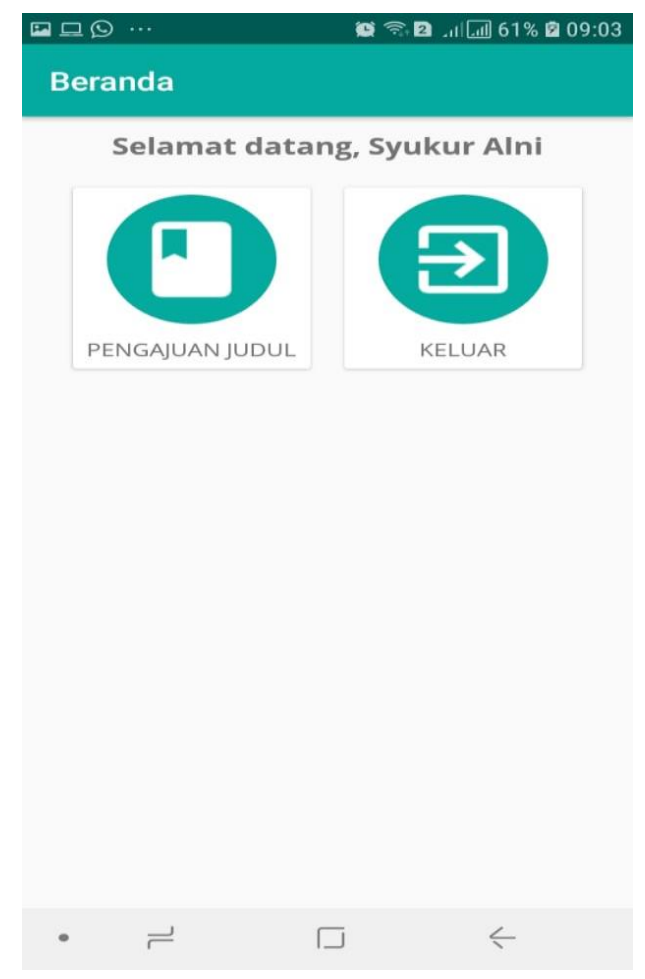

\section{Gambar 9. Halaman Beranda}

Gambar diatas merupakan halaman beranda, halaman ini ditampilkan setiap kali siswa berhasil login ke sistem. Dalam halaman ini akan ditampilkan nama setiap mahasiswa yang login ke sistem. Dan juga terdapat dua icon pilihan yaitu pengajuan judul dan dan keluar. Pengajuan judul untuk melanjutkan mahasiswa ke halaman pengajuan judul. Dan icon keluar untuk keluar dari sistem pengajuan judul.

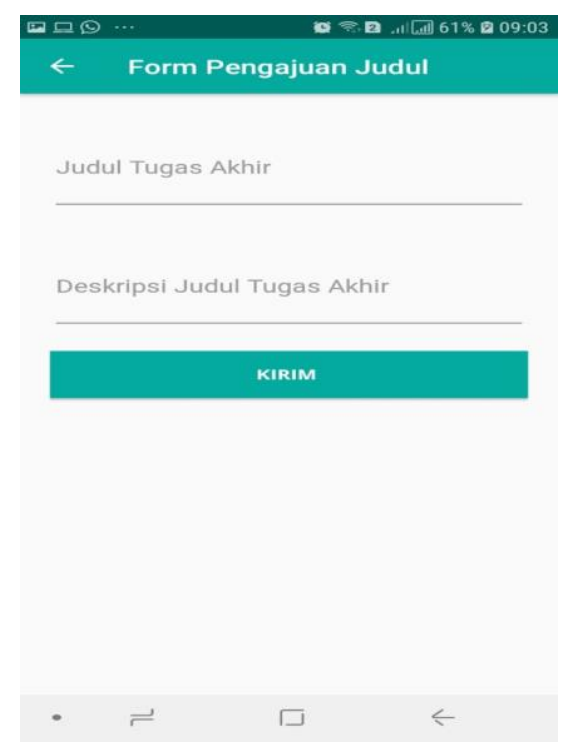

\section{Gambar 10. Halaman Pengajuan Judul}

Halaman pengajuan judul digunakan untuk pengisian judul yang diajukan oleh mahasiswa. Mahasiswa wajib mengisi formulir isian. Pada bagian deskripsi judul, wajib mengisi keterangan singkat mengenai judul yang diangkat. 


\section{KESIMPULAN}

Penelitian ini telah berhasil dilakukan dan memberikan beberapa kesimpulan yaitu: Aplikasi ini dijalankan di smartphone android dan pengguna dibagi 2 (dua) user yaitu Admin yang dalam hal ini ditangani langsung oleh prodi dan pengguna lainnya adalah mahasiswa yang aktif di lingkungan AMIK Mahaputra Riau. Admin dapat mengelola data user secara keseluruhan, seperti melakukan penambahan data mahasiswa, data user, data jadwal seminar.Mahasiswa dapat mengajukan judul tugas akhir secara online dengan smartphone. Hasil pengujian sistem menunjukkan bahwa sistem ini sangat efisien dan efektif, karena mahasiswa dapat dengan mudah mengajukan judul tugas akhir, program studi juga dengan mudah dapat memonitor pelaksanaan tugas akhir.

\section{UCAPAN TERIMAKASIH}

Ucapan terimakasih kami sampaikan kepada Direktorat Riset dan Pengabdian Masyarakat Direktorat Jenderal Penguatan Riset dan Pengembangan Kementrian Riset, Teknologi, dan Pendidikan Tinggi atas pendanaan Penelitian Dosen Pemula (PDP) Tahun Pelaksanaan 2018.

\section{DAFTAR PUSTAKA}

Agustinna, Adriani. Pengembangan aplikasi mobile untuk penyediaan informasi sekitar kampus binus berbasis web

Amin, Ruhul. "Aplikasi akademik online berbasis mobile android pada Universitas tama jagakarsa." Jurnal Sains dan Teknologi Utama, Volume XI, Nomor 1. (2016).

Kamus Besar Bahasa Indonesia (KBBI). [Online]. http://kbbi.web.id/, Mei 2018

Harjono, Lahan. Rancang bangun aplikasi penilaian tugas akhir (TA) berbasis android program studi teknik informatika fakultas teknik universitas muhammadiyah purwokerto. Prosiding SENATEK 2015 Fakultas Teknik, Universitas Muhammadiyah Purwokerto Purwokerto, 28 November 2015, ISBN 978-602-14355-0 -2

Helen Sastypratiwi, Aprillita Dwiyani. Perancangan Aplikasi Daring Bimbingan Tugas Akhir. Jurnal Edukasi dan Penelitian Informatika (JEPIN) Vol. 2, No. 1, (Juni 2016) ISSN 2460-704.

https://developer.android.com/design/getstarted/principles?hl=id
Jogiyanto, Hartono. Analisis \& Desain Sistem Informasi, Andi Offset, Yogyakarta, 2005

Nazruddin, Safaat., H, Pemrograman Aplikasi Mobile Smart phone Dan Tablet PC Berbasis Android, Bandung, Informatika, 2015.

Rosa dan Salahuddin, "Rekayasa Perangkat Lunak terstruktur dan berorientasi Objek", Bandung, Informatika, 2013.

Wahana Komputer, "Panduan Belajar MySQL Database Server", Jakarta, 2010. 